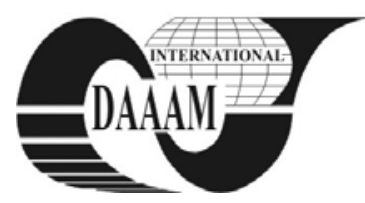

\title{
RISK MANAGEMENT IN VIEW OF THE PRODUCT LIFECYCLE
}

\section{CECHOVA, L[enka] \& SIMON, M[ichal]}

\begin{abstract}
This article deals with the product life cycle, risks and risk management - current state of risk management, description of the risk management process, sources of risk. Eximines the benefits of combination of these two areas. As the greatest benefit can be considered a creation of a risk management methods, which enable to mange risks during all stages of product lifecycle.
\end{abstract}

Key words: product, product lifecycle, risk, risk management

\section{INTRODUCTION}

Organizations of all types and sizes face internal and external factors and influences that make it uncertain whether and when they can achieve their objectives. The effect this uncertainty has on an organization`s objectives is risk. (CSN 31000:2009).

The impact of risk on the organization may have both negative and positive meaning. Negative impact on the organization can be: a danger or personal injury, property and rights violation, security breaches, wasteful use of resources, failure to comply with the quality requirements, damage to reputation, etc. The case of a positive impact is mainly an occasion for added profits.

Risk management is a process in which organization tries to control effects of existing and future factors Risk management process includes the construction of appropriate infrastructure and the use of logical and systematic process to determine the context, identifies, analyses, evaluates, manages, monitors and reports risks associated with any activity, procedure or function in such a way to allow to minimize losses and maximize profits.

Risks are related not only to the organization as a whole, but are part of all activities of the organization. Therefore it is essential for every progressive thinking organization to devote considerable attention to the risks they face. To survive on the market, it is necessary to have executed a design of a comprehensive risk management strategy. The strategy should involve product risk management during each phase of the product lifecycle.

\section{PRODUCT LIFECYCLE}

Each product has a limited lifetime. During this lifetime it passes through a series of states. The concept of particular stages is not clearly given and varies according to perspective (marketing perspective, environment impact perspective, places of implementation perspective). From such lifecycle it is possible to determine the duration of each phase. Each phase brings along characteristic opportunities and threats - risks.

In terms of transformation processes, Professor Hosnedl's lifecycle was selected for risk management. This lifecycle consists of seven phases. All stages are influenced by five operators. Diagram of the lifecycle is shown below.

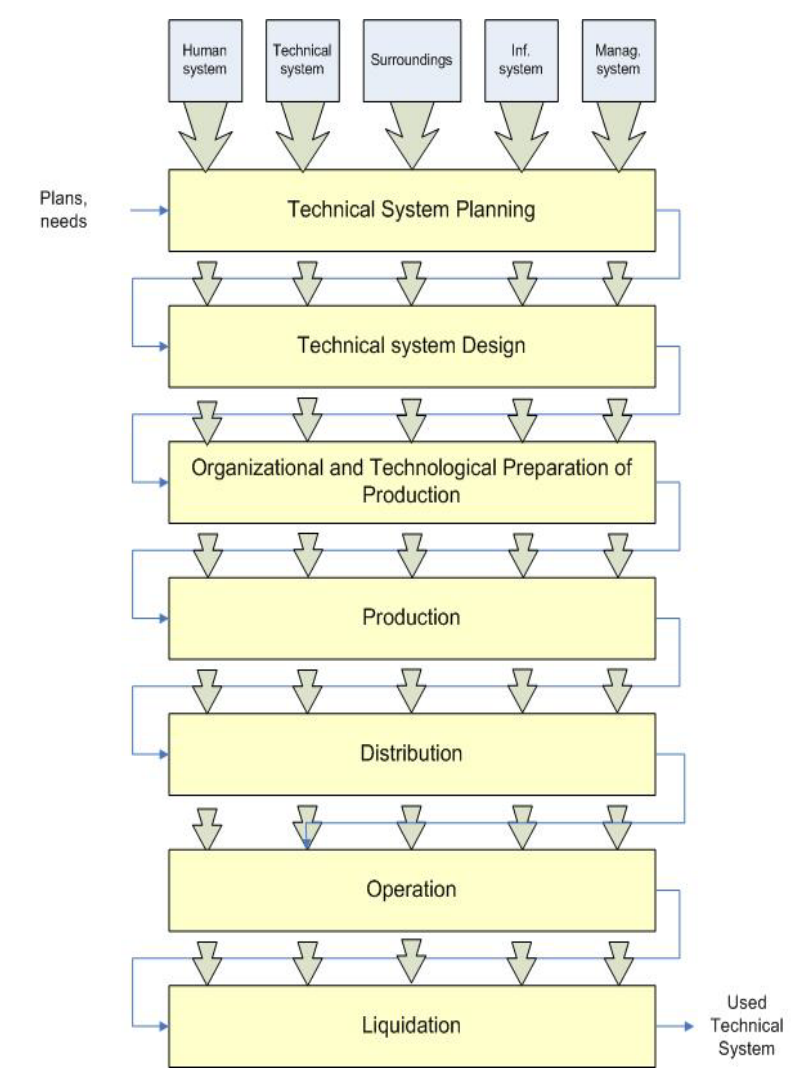

Fig. 1. Simplified product lifecycle scheme by Prof. Hosnedl

\section{RISK MANAGEMENT}

Business risk can be expressed as the possibility of gain or loss on business as a possible deviation from the expected results (negative and positive). Since risk can significantly influence the activities of all organizations, it is necessary to pay attention to their organization and integrate them into their strategic management.

\subsection{The Current State of Risk Management}

Research of the current state of risk management shows that risk management is more increasingly considered an integral part of modern management. More and more organizations realize the need for active risk management and aim to establish or strengthen the system of risk management. Despite this fact a rather intuitive approach to risk management still prevails in organizations.

Risk management is to a large extent greatly burdened by distrust and especially with regard to the need for access to sensitive and strategic information about the organization. Part of risk management of an organization should also be a system for managing product risks during its lifecycle. 


\subsection{Sources of Risk}

Any factor that affects expected outcome may be considered as risk (both positive and negative).

The risk then occurs when this factor is uncertain and its impact significant to the company. For this reason it is necessary to deal with the source of risks itself.

Based on the given product lifecycle, 5 groups of operators are taken as risk sources - man, technical system, the neighborhood (active and reactive), information system, management system. Each of these groups is further broken down into sub-subgroups up to the individual sources of risk.

\subsection{Risk Management}

Risk management can be defined as a set of activities performed by individuals or organizations in effort to modify risk. It is a set of knowledge and procedures, which are focused on the use of possible opportunities while avoiding the adverse effects.

Risk management should be an integral part of management. It should be built into the culture and practices of the organization.

Risk management enables the organization to raise the probability of achieving their goals, improves management and organization of business and serves as a support for decision making.

The process of risk management consists of a sequence of several steps. A number of methods and publications deal with the diversification and description of each step of the risk management process.

For example, the international standard ISO 31000:2009 provides general principles and guidelines for risk management. This international standard can be used for all types of risks, whatever the nature is, and both positive and negative consequences. This document describes the risk management by seven steps. Schematic of the process is captured in the following figure.

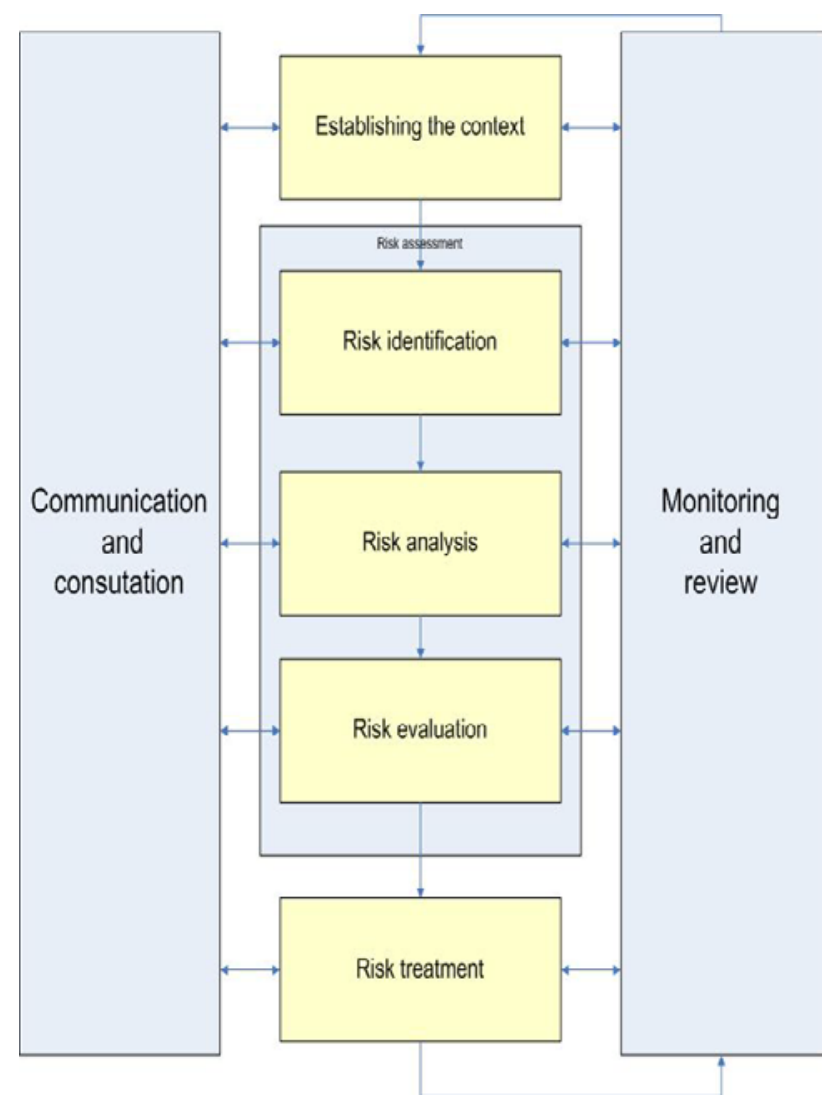

Fig. 2. Risk management scheme
Communication and consultation with external and internal concerned subjects should take place during all stages of the risk management process. They should include dialogue with concerned subjects with an emphasis on bilateral consultations rather than on one way information flow from those who decide to the inferiors.

Monitoring and review are also cross-section activities. They should be planned and should include regular controlling and supervision.

Context assessment means incorporation of the risk management into the rest of the process in which it takes place. At this point it is necessary to understand the organization itself - corporate culture, internal interest groups, organization structure, available resources, aims and objectives, including the strategies outlined to achieve them.

Risk assessment consists of three steps - identification, risk analysis and risk evaluation.

Risk identification is used to detect risks. It is necessary to pay attention to this stage of risk management. Risks that are not included at this stage will not be analyzed further.

Risk analysis means the developing of understanding risks. Analysis provides input for risk evaluation and for deciding which risks need to be treated and for choosing the most suitable strategies and methods for their treatment.

Risk evaluation is a process of comparing the results of risks analysis with risks criteria. It serves to determine whether the risk and its size are acceptable for the organization or not.

The last step of risk management is risk treatment. This step includes the selection of strategies and methods and their implementation to change the risk.

\section{CONCLUSION}

If we succeeded to connect these two fields and create methodology, it would be possible to manage the product risks throughout the product's lifecycle

This connection would be useful especially in phases when considering the adoption of the product, where it would allow an expressed risk ratio of the product during its whole lifecycle and during the individual life stages.

Further this connection would serve after the product acceptance, when it would allow the management of risks and subsequent treatment of them during their individual life stages.

\section{ACKNOWLEDGEMENTS}

This paper was supported by Internal Grant Agency of University of West Bohemia. Project No. SGS-2010-065 "Multidisciplinary Design Optimization and Operation of production system in digital factory environment.”

\section{REFERENCES}

Crouhy, D.; Galai, D. \& Mark, R. (1991). The Essentials of Risk Management,'McGraw-Hill, ISBN 978-0071429665, New York

Dvorak, J.: (2011) Risk Management of Technical Products in Their Life Cycle, Sbornik prispevku - Soutezni prehlidka studentskych a doktorskych praci FST 2011. Eds.: P. Zitek, ISBN 978-80-7043-995-1, Pilsen

Hnilica, J.; Fotr, J. (2009). Aplikovana analyza rizik ve financnim managementu a investicnim rozhodovani, Grada Publishing, ISBN 978-80-247-2560-4, Praha

Merna, T.; Al-Thani, F. (2007). Risk amnagement, Computer Press, ISBN 978-80-251-1547-3, Brno

Idt. CSN 31000:2009 Czech vision of International Standard ISO 31000:2009 - Risk Management - principles and Guidelines, Praha 